\title{
ПРИМЕНЕНИЕ ФИЗИЧЕСКОЙ СИЛЫ ДОБРОВОЛЬНЫМИ НАРОДНЫМИ ДРУЖИННИКАМИ, В РАМКАХ ФЕДЕРАЛЬНОГО ЗАКОНА ОБ УЧАСТИИ ГРАЖДАН В ОХРАНЕ ОБЩЕСТВЕННОГО ПОРЯДКА»: ВОПРОСЫ ТЕОРИИ
}

\begin{abstract}
Аннотация: Объектом исследования являются общественные отношения в сфере применения добровольными народными дружинниками физической сильл. Особое внимание уделяется законности и основаниям применения физической силь дружинниками, в цүелях самозащить, защить третьих лиц и обеспечительной меры, для выполнения некоторых из задач. Автор подробно рассматривает вопросы соотношения необходимой обороны в рамках федерального закона «Об участии граждан в охране общественного порядка» и Уголовного кодекса РФ, вопросы правомерности задержания правонарушителей и лии застигнутых на месте совершения преступления дружинниками. В ходе исследования проведено сравнение законодательства, регулирующего деятельность дружинников, с законом «О полищии», также были использованы нормы УК РФ, и КоАП РФ, с иелью изучения возможностей применения физической силь дружинниками и соответствия этих возможностей законодательству. В ходе исследования изучена судебная практика сложившаяся с момента вступления закона в силу и приведен краткий обзор зарубежного опыта (Белоруссия, Таджикистан, Япония, Великобритания) деятельности лиц, принимающих участия в охране общественного порядка и возможности применения физической силь данныли лицами. С момента вступления федерального закона «Об участии граждан в охране общественного порядка» прошло более двух лет, однако вопросы применения физической силь дружинниками не исследованы, в законодательстве имеются коллизии с уголовным законодательством, не отрегулирован вопрос применения физической силь дружинниками, как обеспечительной меры, что ставит под сомнение возможность реализации возложенных на них задач в полном объеме. Правовые аспекты применения физической силь должны иметь единый знаменатель в действуюшем законодательстве, чего в настоящее время не наблюдается.
\end{abstract}

Ключевые слова: Ответственность дружинника, меры обеспечения, дружинник, применение физической силь, крайняя необходимость, необходимая оборона, добровольная народная дружсин, обеспечение общественного порядка, задержание, меры принуждения.

Abstract: The object of this research is the public relations in the area of use of physical force by the members of Voluntary People's Druzhina. A special attention is given to the legality and grounds for use of physical force by druzhinniks in self-defense, protection of third parties, and execution of their tasks. The author carefully examines the questions of correlation of the necessary defense within the frameworks of the Federal Law "On Participation of Citizens in Maintenance of Public Order" and Criminal Code of the Russian Federation, as well as the questions of legality of detention of individuals caught by druzhinniks at the scene of the crime. The author conducted comparative analysis of the legislation that regulates the work of druzhinniks with the law "On Police", and used the norms of the Criminal Code of the Russian Federation and Code of the Russian Federation on Administrative Offenses for the purposes of studying the possibilities of use of physical force by druzhinniks and correspondence of this use with the legislation. The work presents the research on the legal precedent from the moment the law went into force, as well as review of the foreign precedent (Belarus, Tajikistan, Japan, and $U K)$ on cases of use of physical force by members of law enforcement.

Keywords: Voluntary People's Druzhina, Necessary defense, Absolute necessity, Measures, Druzhinnik, Use of force, Responsibility, Public order, Detention, Compulsion measures.

2014 г. вступил в силу Федеральный закон «Об участии граждан в охране общественного порядка» (далее Ф3-44) [1], принятие которого свидетельствует о заинтересованности государства в вовлечении общественности в деятельность по охране общественного порядка. Несмотря на положительные моменты от принятия данного закона, связанные с большей вовлеченностью общества в дела государства, возможности повышения уровня правовой культуры, через участие в мероприятиях по охране 
общественного порядка, установлении плотного взаимодействия между обществом и правоохранительными органами (в большей степени с полицией) в решении общественно-значимых задач в области укрепления правопорядка, закон содержит некоторые спорные моменты требующие плотного теоретикоправового анализа. Одним из таких вопросов является применение физической силы добровольными народными дружинниками.

Применение физической силы в состоянии крайней необходимости и необходимой обороны закреплено в статье 19 Ф3-44 [1]. Рассматривая применение физической силы добровольными дружинниками в состоянии необходимой обороны, подчеркнем, необходимая оборона является институтом уголовного права. Ф3-44 устанавливает особый порядок применения физической силы в состоянии необходимой обороны, заключающийся в сообщении лицу, в отношении которого применятся физическая сила о своем намерении [1]. Лишь в некоторых случаях, связанных с угрозой жизни и здоровья дружинник имеет право не предупреждать о применении физической силы [1]. В соответствии со ст. 37 УК РФ, положения статьи о необходимой обороны распространяются на всех граждан, независимо от степени профессиональной и физической подготовки. По данной причине закрепление права на применение физической силы в состоянии необходимой обороны в рамках Ф3-44 представляется нецелесообразным, поскольку наличие особого порядка, связанного с предупреждением дружинником лица о своем намерении и предоставлении возможности для прекращения действий, с одной стороны противоречит ст. 37 УК, с другой стороны схожа с порядком применения физической силы сотрудниками полиции. Однако тождественность порядка применения физической силы сотрудниками полиции и дружинниками представляется весьма спорной, исходя из различных целей применения физической силы полицейскими [4] и дружинниками [1]. Применение физической силы сотрудниками полиции имеет характер мер административного пресечения, применение физической силы же дружинниками, в рамках закона направленно на устранение опасности для жизни и здоровья. Тождественность в порядке применении физической силы полицейскими и дружинниками проявляется в предоставлении возможности для прекращения действий либо выполнении требований и возможности применения физической силы без предупреждения если промедление в ее применении создает непосредственную угрозу жизни и здоровью граждан, лица, применяющего физическую силу (сотрудника полиции или дружинника) либо иные тяжкие последствия. Также идентичность в порядке применения физической силы дружинниками и полицейскими проявляется в обязательном оказании первой помощи лицу, пострадавшему от применения физической силы, уведомлении командира либо руководителя о получении гражданином телесных повреждений и о запрете применять физическую силу в отношении женщин с видимыми признаками беременности, лиц с явными признаками инвалидности, несовершеннолетних, когда их возраст очевиден или известен, за исключением совершения группового, либо вооруженного нападения.

Как справедливо констатируют О.И. Бекетов и Н.В. Шухман: «В законе не проводится разграничения между необходимостью и возможностью применения физической силы» [5] для добровольных народных дружинников и предлагают оставить лишь требование дружинников о прекращении противоправных деяний, признавая излишним сообщение о намерении применить физическую силу. На наш взгляд, с одной стороны данное требование справедливо, но все-таки имеется противоречие, как отмечалось выше со ст. 37 УК РФ, и порядок применения физической силы в состоянии необходимой обороны тожественен порядку применения физической силы сотрудниками полиции. По данной причине, на наш взгляд из закона следует исключить особый порядок применения физической силы в состоянии необходимой обороны и крайней необходимости.

Также вызывает вопрос, почему ст. 19 Федерального закона «Об участии граждан в обеспечении общественного порядка» закреплено за дружинниками право на применение физической силы необходимой обороны и крайней необходимости, но отсутствует такое основание, как задержание лица совершившего преступления. Логика законодателя представляется туманной - дружинник имеет право применять физическую силу только в состоянии необходимой обороны и крайней необходимости, либо применять физическую силу для задержания лица совершившего преступления он имеет в общем порядке?

По мнению автора, применять физическую силу для задержания лица дружинник имеет в общем порядке, исходя из положений ст. 38 УК РФ и Постановления Пленума Верховного Суда: «Право на задержание лица, совершившего преступление, имеют не только уполномоченные на то представители власти, но и иные лица, в том числе пострадавшие от преступления, или ставшие его непосредственными очевидцами, или лица, которым стало достоверно известно о его совершении» [6].

Возможна такая ситуация, когда задержание лица трансформируется в необходимую оборону, о 
чем указывает судебная практика [7]. В таком случае квалификация происходит по правилам необходимой обороны. Налицо парадоксальная ситуация, например, дружинник в ходе обхода территории является свидетелем причинения телесных повреждений гражданину, после чего лицо причинившее вред скрывается. Дружинник задерживает лицо, в порядке ст. 38 УК РФ, в общем порядке, в момент задержания лицо начинает посягательство на жизнь дружинника, и причиняет последнему телесные повреждения. В этот момент у дружинника появляется право на необходимую оборону, однако в соответствии со ст. 19 Ф3-44 в этот момент дружинник должен сообщить о том, что он является дружинником, и о намерении применить физическую силу. И это после того, как физическую силу дружинник уже начал применять на законных основаниях. Конечно, дружинник имеет право не предупреждать о своих намерениях, однако для этого должно быть основание в виде наличия непосредственной угрозы жизни и здоровья. То есть дружинник должен прервать задержание, сообщить все необходимые данные, после чего продолжить задержание. Для предотвращения таких курьезных, в отрицательном смысле ситуаций, на наш взгляд необходимо изменить бланкетный характер нормы, для предотвращения коллизий исключив особый порядок применения физической силы дружинниками.

Применение физической силы в теории является мерой принуждения и не всегда связано с пресечением попыток причинения вреда жизни и здоровью, также физическая сила может применяться для задержания лица, для пресечения попыток правонарушения, оставления лица в территориальный орган внутренних дел, «попытки избавится от предметов, являющихся вещественными доказательствами, либо самовольно покинуть место происшествия» [8].

Однако в отношении дружинников совершенно четко установлена возможность применения физической силы лишь для устранения опасностей угрожающих жизни и здоровью дружинника и третьих лиц. Такой подход, как справедливо отмечает В.И. Горбунов лишает дружинников смысла требовать прекратить противоправные деяния, так как, при невыполнении законных требований применяются меры «специального характера, одной из которых является применение физической силы» [8], и принимать меры по охране места происшествия, поскольку при попытке покинуть место происшествия дружинник, фактически не может оказать противодействия лицу.

На наш взгляд подход к определению порядка и оснований применения физической силы добро- вольными народными дружинниками требует кардинального пересмотра, поскольку действующие нормы создают с одной стороны коллизии с уголовноправовым законодательством, с другой не обеспечивают возможности выполнения задач дружинников в должном объеме. Автор предлагает иной подход к определению порядка применения физической силы дружинниками. Во-первых исключить бланкетный характер нормы, для предотвращения коллизий с уголовным законодательством. Во-вторых, на наш взгляд, применение физической силы дружинниками, как обеспечительной меры противоречит ч. 1 ст. 27.1 КоАП РФ, закрепляющие, что правом на применение физической силы, как меры обеспечения, обладают лишь уполномоченные на то должностные лица. В связи с этим требуется исключить из Ф3-44 некоторые из прав дружинников, например на принятие мер, по охране места происшествия, требования о прекращении противоправного деяния, поскольку данные права являются декларативными и их исполнение никак не обеспечено.

В рамках изучения такого неоднозначного вопроca, как применение физической силы добровольными народными дружинниками, представляется возможным изучить опыт некоторых зарубежных стран для его возможного дальнейшего использования с учетом особенностей российской правовой системы и стратегии правого регулирования в вопросах участия граждан в обеспечении общественного порядка.

Так, изучая опыт стран СНГ по данной теме, в Республике Беларусь с 2003 г. действует закон Республики Беларусь от 26 июня 2003 года №214-3 «Об участии граждан в охране правопорядка». [9] Данный закон закрепляет за дружинниками прямое право на применение физической силы, как меры обеспечения, для задержания лица и доставления его в правоохранительные органы, если другими способами выполнить функцию, по обеспечению правопорядка не представляется возможным. Порядок применения физической силы имеет сходство с порядком задержания правонарушителя сотрудниками полиции (предупредить, дать время прекратить действия и т.д.), превышение полномочий дружинником, направленных на задержание влечет ответственность.

В Таджикистане [10] порядок применения физической силы имеет сходство с Белоруссией за исключением запрета применения физической силы в отношении несовершеннолетних, женщин с явными признаками беременности и инвалидов, без каких-либо оговорок. Порядок же в Белоруссии предполагает применение физической силы в отношении данной категории лиц, в случае совершения вооруженного 
и группового нападения. В данном вопросе более приемлемым видится опыт Таджикистана, поскольку совершение группового нападения указанными категориями дает возможность на применение физической силы в порядке необходимой обороны, без соблюдения установленного порядка действий.

Белорусская же модель не делает разграничения между необходимой обороной и применением физической силы для задержания. В связи с этим остается не достаточно ясным, в каком случае дружинник действует в рамках законодательства о дружинниках, а в каком в рамках УК.

Опыт Великобритании в привлечении граждан в деятельность по охране общественного порядка заслуживает внимания, поскольку включает в себя более 40 лет успешного взаимодействия (с 1973 года) [11 с. 122] В Великобритании имеются как противники, так и сторонники участия граждан в охране общественного порядка. Основным аргументом противников, является, то, что охранять общественный порядок должны специально подготовленные специалисты, для которых это является основной сферой деятельности. В некоторой степени аргумент справедливый, и в Великобритании был найден компромисс по вопросу участия граждан, так одной из форм является патрулирование и информирование правоохранительных органов, а также высказывание замечания лицам нарушающим общественный порядок [11 с. 122] На наш взгляд такая модель является наиболее оптимальной, поскольку не ставит дружиннику задачей прекратить действия нарушающие общественный порядок. Применение физической силы, как обеспечительной меры в данном случае.

Применение же физической силы дружинниками физической силы, в качестве необходимой обороны в Великобритании возможно в общем порядке, в соответствии с Законом об общей юстиции 1967 г., который закрепляет возможность применения «разумной силы», для предупреждения преступления, либо для производства законного ареста преступника [12].

Японская модель участия граждан в обеспечении общественного порядка предполагает, в большей мере, работу, связанную с профилактикой преступлений, а не пресечением и задержанием правонарушителей. На районном уровне созданы пункты предупреждения преступности, задачей которых является информирование полиции о происшествиях и несчастных случаях, проведения просветительской работы среди населения, по вопросам правопорядка и проведение бесед с населением [13]. При такой модели применение физической силы является необходимым, лишь в качестве защиты от посягательства.
Краткий обзор деятельности регулирования деятельности дружин позволил сделать вывод, что наиболее оптимальным будет является установление основного вектора деятельности народных дружин на деятельность связанную с профилактикой противоправных деяний ( обходы, беседы, собрания на предприятиях) и сообщение в правоохранительные органы о действиях, нарушающих общественный порядок. На наш взгляд, не является необходимым устанавливать дружинникам задачи (требование прекратить действия нарушающие общественный порядок), требующие обязательного установления обеспечительных мер, в случае невыполнения требований, связанных с непосредственным контактом с нарушителем (задержание, доставление и т.д), поскольку данной деятельностью должны заниматься профессионалы, прошедшие специальную подготовку.

Для определения дальнейшего направления развития деятельности дружинников, автор провел изучение судебной практики связанной с деятельностью дружинников с момента вступления Ф3-44 в силу. Можно выделить несколько основных направлений деятельности дружинников, встречающихся на практике: участие в качестве понятого при проведении процессуальных действий [14-16], совместное патрулирование территории с сотрудников полиции [1720], участие в доставлении нарушителя совместно с сотрудником полиции[21-22] и участие в регулировании безопасности дорожного движения совместно с сотрудником полиции [23-25]. Также встречаются единичные случаи, когда дружинники, в отсутствии инспектора ГИБдД производят остановку транспортного средства и просят нарушителя подождать инспектора [26] Также изредка встречаются случаи применения физической силы дружинниками, как меры принуждения. Например, в 2015 г. во Фрунзенском районном суде рассматривалось дело факту неповиновения законным требованиям сотрудника полиции. Сотрудник полиции нес службу совместно с дружинником, и дружинник совместно с сотрудником полиции применил физическую силу для задержания нарушителя. Было вынесено решение о привлечении виновного лица к ответственности, апелляции в городском суде и возвращения на новое производства решение не изменилось [13]. Также в практике имеется случай самостоятельного задержания дружинниками лица, управлявшего транспортным средством в состоянии опьянения и транспортного средства. После задержания о факте было сообщено в дежурную часть и после прибытия сотрудников полиции нарушитель был передан для составления процессуальных документов [27] 
Сложившаяся практика деятельности дружинников, нашедшая отражение в судебных решениях демонстрирует, что в настоящее время дружинники, в большей степени охраняют общественный порядок совместно с сотрудниками полиции, факты самостоятельной деятельности дружинников, связанные с задержанием нарушителей и автомобиля, самостоятельной остановки транспортного средства носят единичный характер и вопросов о правомерности действий у суда не вызывают. Анализ судебной практики позволяет сделать вывод, что для преодоления споров в вопросах правомочности применения физической силы дружинниками необходима определенность в законе. Например, это может быть закрепление, возможности применения физической силы, в качестве меры принуждения в связи с задержанием правонарушителя при осуществлении совместного патрулирования с сотрудником полиции, по указанию сотрудника полиции. Случаи инициативы в осуществлении действий направленных на задержание дружинников, как отмечалось выше носят единичный характер, поэтому

Подводя окончательный итог, автор предлагает исключить особый порядок применения физической силы народными дружинниками, поскольку представители дружин в настоящее время не являются субъектами, имеющими на применение физической силы в специальном порядке. Для дружинников возможен, как и для всех граждан РФ, лишь общий порядок, включающий необходимую оборону, задержание лица совершившего преступление и крайняя необходимость.

Также необходимо назаконодательном уровнеподнять вопрос о материальной ответственности народных дружинников, за вредпричинённый на законных основаниях.

Вопросы применения физической силы народными дружинниками требуют дальнейшего совер- шенствования с привлечением специалистов теории государства и права, уголовного права, административного права, и гражданского права. Привлечение специалистов в вышеуказанных отраслях права необходимо для осмысления и развития вопросов необходимой обороны, крайней необходимости, задержания лица, застигнутого на месте преступления, возможности применения дружинниками мер административного принуждения и вопросов гражданско - правовой ответственности за причиненный вред в деятельности добровольных народных дружинников.

Как показывает практика дружинники активно участвуют в совместном задержании правонарушителей с сотрудниками полиции, в связи с этим возможно, как отмечалось выше, на применение физической силы, при совместном задержании с сотрудником полиции, по указанию сотрудника. В первую очередь это необходимо, чтобы обезопасить, как дружинников от необоснованных претензий со стороны граждан, с другой, чтобы предотвратить злоупотребление предоставленным правом, при самостоятельной деятельности дружинников.

Также необходимо более тщательно проанализировать зарубежный опыт по данному вопросу, чего в рамках статьи сделать не представляется возможным и извлечь полезные уроки. Например, как автор отмечал выше построить деятельность дружин таким образом, чтобы их задачи, при осуществлении самостоятельной деятельности не требовали применения физической силы, направив основную деятельность, связанную с самостоятельной работой на профилактику и на патрулирование с сообщением в правоохранительные органы о фактах нарушения общественного порядка. В дальнейшем уже возможно участие в задержании лица, но только совместно с сотрудником полиции.

\section{Библиография:}

1. Федеральный закон от 2 апреля 2014 г. № 44-Ф3 «Об участии граждан в охране общественного порядка» // Собрание законодательства Российской Федерации от 7 апреля 2014 г. N 14 ст. 1536

2. Уголовный кодекс Российской Федерации от 13.06.1996 № 63-Ф3 (ред. от 02.06.2016) // СПС «Консультант плюс»

3. Ст.ст. 19, 20-23 Федерального закона от 07.02.2011 № 3-Ф3 (ред. от 23.06.2016) «О полиции» // СПС «Консультант плюс»

4. Бекетов О.И.; Шухман Н.В. Комментарий к Федеральному закону от 2 апреля 2014 г. № 44-Ф3 «Об участии граждан в охране общественного порядка» (подготовлен для системы «Консультант Плюс») // СПС «Консультант Плюс».

5. п. 18-19 Постановления Пленума Верховного Суда РФ от 27 сентября 2012 г. № 19 «О применении судами законодательства о необходимой обороне и причинении вреда при задержании лица, совершившего преступление» // Бюллетень Верховного Суда Российской Федерации, ноябрь 2012 г., № 11

6. Горбунов В.Ю. Дефекты механизма реализации гражданами полицейских полномочий в области охраны общественного порядка и обеспечения общественной безопасности // Юридическая наука и правоохранительная практика. Тюмень: Тюменский институт повышения квалификации сотрудников МВД РФ, 2015 г. - № 4 (34), С. 140-147

7. Корнев А.С. Об устранении и восполнении пробелов в правев связи с устареванием действующего законодательства // Вопросы экономики и права. - 2014 г. - № 76 С. 7-9.

8. Щербаков О.Н. Отдельные аспекты участия граждан в охране общественного порядка // Административное и муниципальное право. - 2016. - 5. - C. 382 - 386. DOI: 10.7256/1999-2807.2016.5.16772. 
9. Закон Республики Беларусь от 26 июня 2003 года №214-3 «Об участии граждан в охране правопорядка» (ред. от 04.01.2014) // http://base.spinform.ru/show_doc.fwx?rgn=3691 (дата обращения 07.07.2016)

10. Закон республики Таджикистан «Об участии граждан в охране общественного порядка» № 566 от 03.12.2009 // antitip. tj)ru/files/uchastgrazhdan.doc (дата обращения 07.07.2016)

11. Егорышев С.В. Из зарубежного опыта взаимодействия правоохранительных органов с общественностью// Вестник Экономической безопасности. - М. : Московский университет МВД России, 2008 г. С.121-125

12. Капинус О.С. Необходимая оборона и крайняя необходимость по уголовному законодательству зарубежных стран // Вестник Академии генеральной Прокуратуры. - М.: 2008 г. - № 3-5 С.41

13. Нечевина Н.Д.. Правовое Регулирование участия граждан в обеспечении правопорядка в современный период // Российский следователь. - М.: [б.н.], 2005 г. - № 7. С. 43

14. Постановление Верховного суда Удмуртской республики № 4A-24/2016 4A-852/2015 от 26 января 2016 г. по делу № 4A24/2016//https://vs--udm.sudrf.ru/modules.php?name=sud_delo\&name_op=doc\&srv_num=1\&number=788412\&delo_ $\mathrm{id}=2550001 \&$ new $=\&$ text_number=1\&case_id=744154 (дата обращения 08.07.2016)

15. Приговор Сызранского городского суда (Самарская область) № 1-44/2016 1-702/2015 от 27 января 2016 г. по делу № 1-44/2016 // https://syzransky--sam.sudrf.ru/modules.php?name=sud_delo\&srv_num=1\&name_op=doc\&number=40307902\&delo_ id=1540006\&new=0\&text_number=1 (дата обращения 08.07.2016)

16. Приговор Анапского городского суда (Краснодарский край) № 1-172/2015 от 11 декабря 2015 г. по делу № 1-172/2015 // http://судебныерешения.pф/bsr/case/7686941 (дата обращения 08.07.2016)

17. Приговор Выселковского районного суда (Краснодарский край) № 1-182/2015 от 11 ноября 2015 г. по делу № 1-182/2015 // https://viselkovsky--krd.sudrf.ru/modules.php?name=sud_delo\&srv_num=1\&name_op=doc\&number=73574330\&delo_ id $=1540006 \&$ new $=0 \&$ text number $=1$ (дата обращения 08.07.2016)

18. Постановление Новоалтайского городского суда (Алтайский край) № 5-1245/2015 от 3 октября 2015 г. по делу № 5-1245/2015 // https://novaltaisky--alt.sudrf.ru/modules.php?name=sud_delo\&name_op=doc\&srv_num=1\&number=23938036\&delo_ id $=1500001 \&$ new $=\&$ text number $=1 \&$ case $\mathrm{id}=23625963$ (дата обращения 08.07.2016)

19. Приговор Октябрьского городского суда (Самарская область) № 1-93/2015 от 1 октября 2015 г. по делу № 1-93/2015 // https://oktiabrsky--sam.sudrf.ru/modules.php?name=sud_delo\&srv_num=1\&name_op=doc\&number=33061988\&delo_ id $=1540006 \&$ new $=0 \&$ text_number=1 (дата обращения 08.07.2016)

20. Приговор Первоуральского городского суда (Свердловская область) № 1-60/2015 1-618/2014 от 19 марта 2015 г. по делу № 1-60/2015 // https://pervouralsky--svd.sudrf.ru/modules.php?name=sud_delo\&name_op=doc\&srv_ num $=1 \&$ number $=56153564 \&$ delo $\mathrm{id}=1540006 \&$ new $=\&$ text number=1 (дата обращения 08.07.2016)

21. Постановление Центрального районного суда г. Сочи (Краснодарский край) № 1-123/2016 1-126/2016 от 9 марта 2016 г. по делу № 1-123/2016 // http://sudact.ru/regular/doc/zTEISvfNE765/?regular-txt=®ular-case_doc=1-

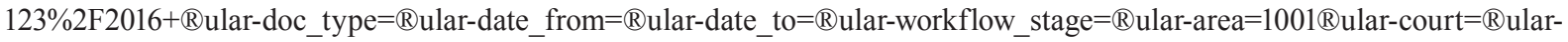
judge $=\& \_=1467966797642$ (дата обращения 08.07.2016)

22. Постановление № 1 Автозаводского районного суда г. Тольятти (Самарская область) 975/2015 от 27 ноября 2015 г. по делу № 1-975/2015 // https://bsr.sudrf.ru/bigs/showDocument.html?id=9967eeec59efe98b6cf1ef48cf85daa9\&shard=Уголов ные дела\&fieldName=court_document_documentext1_tag\&from=p (дата обращения 08.07.2016)

23. Решение Дзержинского районного суда г. Волгограда № 12-74/2016 12-805/2015 от 14 января 2016 г. по делу № $12-$ 74/2016 // https://bsr.sudrf.ru/bigs/showDocument.html?id=8a2289e127afable7db781b6518f0c85\&shard=Административн ые дела\&fieldName=court document_documentext1 tag\&from=p(дата обращения 08.07.2016)

24. Решение Тракторозаводского районного суда г. Волгограда от 11 декабря 2015 г. по делу № 12-331/2015; // https://trac-vol.sudrf.ru/modules.php?name=sud_delo\&srv_num=1\&name_op=doc\&number=79506240\&delo_id=1502001\&new $=0 \&$ text number=1 (дата обращения 08.07.2016)

25. Решение Красногвардейского районного суда г. Санкт-Петербурга № 12-374/14 от 14 ноября 2014 г. //https://kgv--spb. sudrf.ru/modules.php?name=sud_delo\&srv_num=1\&name_op=doc\&number $=55803738 \& d e l o \_i d=1502001 \&$ new $=0 \&$ text number=1 (дата обращения 08.07.2016)

26. Решение Можгинского районного суда (Удмуртская республика) от 3 марта 2016 г. по делу № 12-24/2016 // https:// mozhginskiygor--udm.sudrf.ru/modules.php?name=sud_delo\&srv_num=1\&name_op=doc\&number=48071391\&delo_ id=1502001\&new=0\&text_number=1 (дата обращения 08.07.2016)

27. Решение Одинцовского городского суда Московской области по делу № 12-871/14 // https://odintsovo--mo.sudrf. $\mathrm{ru} /$ modules.php?name=sud_delo\&name_op=doc\&srv_num $=1 \&$ number $=119887882 \&$ delo_id $=1502001 \&$ new $=\&$ text number=1(дата обращения 08.07.2016)

28. Босхамджиева Н.А., Кашкина Е.В. Административно-правовое регулирование взаимодействия органов внутренних дел с институтами гражданского общества в сфере предупреждения правонарушений // Административное и муниципальное право. - 2010. - 9. - С. 13 - 17.

\section{References (transliterated):}

1. Beketov O.I.; Shukhman N.V. Kommentarii k Federal'nomu zakonu ot 2 aprelya 2014 g. № 44-FZ «Ob uchastii grazhdan v okhrane obshchestvennogo poryadka" (podgotovlen dlya sistemy «Konsul'tant Plyus») // SPS «Konsul'tant Plyus».

2. Gorbunov V.Yu. Defekty mekhanizma realizatsii grazhdanami politseiskikh polnomochii v oblasti okhrany obshchestvennogo poryadka i obespecheniya obshchestvennoi bezopasnosti // Yuridicheskaya nauka i pravo- 
DOI: $10.7256 / 1811-9018.2016 .7 .19604$

При цитировании этой статьи сноска на doi обязательна

Закон и правопорядок

okhranitel'naya praktika. - Tyumen': Tyumenskii institut povysheniya kvalifikatsii sotrudnikov MVD RF, 2015 g. - № 4 (34), S. 140-147

3. Kornev A.S. Ob ustranenii i vospolnenii probelov v pravev svyazi s ustarevaniem deistvuyushchego zakonodatel'stva // Voprosy ekonomiki i prava. - 2014 g. - № 76 S. 7-9.

4. Shcherbakov O.N. Otdel'nye aspekty uchastiya grazhdan v okhrane obshchestvennogo poryadka // Administrativnoe i munitsipal'noe pravo. - 2016. - 5. - C. 382 - 386. DOI: 10.7256/1999-2807.2016.5.16772.

5. Egoryshev S.V. Iz zarubezhnogo opyta vzaimodeistviya pravookhranitel'nykh organov s obshchestvennost'yu// Vestnik Ekonomicheskoi bezopasnosti. - M. : Moskovskii universitet MVD Rossii, 2008 g. S.121-125

6. Kapinus O.S. Neobkhodimaya oborona i krainyaya neobkhodimost' po ugolovnomu zakonodatel'stvu zarubezhnykh stran // Vestnik Akademii general'noi Prokuratury. - M.: 2008 g. - № 3-5 S.41

7. Nechevina N.D.. Pravovoe Regulirovanie uchastiya grazhdan $v$ obespechenii pravoporyadka v sovremennyi period// Rossiiskii sledovatel'. - M.: [b.n.], 2005 g. - № 7. S. 43

8. Boskhamdzhieva N.A., Kashkina E.V. Administrativno-pravovoe regulirovanie vzaimodeistviya organov vnutrennikh del $\mathrm{s}$ institutami grazhdanskogo obshchestva $\mathrm{v}$ sfere preduprezhdeniya pravonarushenii // Administrativnoe i munitsipal'noe pravo. $-2010 .-9 .-$ C. $13-17$. 